Supporting information

\title{
Regulating Coordination Environment in Metal-Organic Frameworks for Adsorption and Redox Conversion of Polysulfides in Lithium-Sulfur Batteries
}

Yingbo Xiao, ${ }^{1}$ Wei Gong, ${ }^{1}$ Sijia Guo, ${ }^{1}$ Yuan Ouyan, ${ }^{1}$ Dixiong Li, ${ }^{1}$ Xin Li, ${ }^{1}$ Qinghan

Zeng, ${ }^{1}$ Wenchao He, ${ }^{1}$ Haoyan Deng, ${ }^{1}$ Chao Tan, ${ }^{1}$ Qi Zhang ${ }^{1,2 *}$ and Shaoming Huang ${ }^{1,2 *}$

${ }^{1}$ Guangzhou Key Laboratory of Low-Dimensional Materials and Energy Storage Devices, School of Materials and Energy, Guangdong University of Technology, Guangzhou, 510006, People's Republic of China.

${ }^{2}$ Synergy Innovation Institute of GDUT, Heyuan, 517000, People's Republic of China.

Email for Q.Z.: qzhangmse@gdut.edu.cn

Email for S.H.: smhuang@gdut.edu.cn 


\section{EXPERIMENTAL SECTION}

Materials. Graphene oxide (GO) and carbon nanotubes (CNTs) were obtained from Nanjing XFNANO Material Technology Co., Ltd (China). Ascorbic acid and Bismuth nitrate pentahydrate $\left(\mathrm{Bi}\left(\mathrm{NO}_{3}\right)_{3} \cdot 5 \mathrm{H}_{2} \mathrm{O}\right)$ were purchased from Sinopharm Chemical Reagent Co. Ltd (China). Carbon paper was obtained from Hesen Electric Inc. Shanghai. Lithium-metal foil was obtained from Tianjin zhongneng lithium Co. Ltd (China). Other reagents, unless otherwise stated, were obtained from commercial sources (Sigma Aldrich, Alfa Aesar) and were used without further purification.

Synthesis of rGO. $30 \mathrm{mg}$ of ascorbic acid and $70 \mathrm{mg}$ of GO were dispersed in $35 \mathrm{ml}$ of distilled water (DIW) followed by sonication and vigorous stirring for $45 \mathrm{~min}$. Then, resulting solution was transferred to autoclave, heated to $90{ }^{\circ} \mathrm{C}$ for $1 \mathrm{~h}$. After cooled to room temperature, the black precipitate was collected by filtration, washed alternately with DIW, and freeze drying overnight to obtain the rGO.

Synthesis of Bi-MOF-1. CAU-17 was firstly prepared by solvothermal method reported in the literature. ${ }^{1}$ In a typical synthesis, $750 \mathrm{mg}$ of $\mathrm{H}_{3} \mathrm{BTC}$ and $150 \mathrm{mg}$ of $\mathrm{Bi}\left(\mathrm{NO}_{3}\right)_{3} \cdot 5 \mathrm{H}_{2} \mathrm{O}$ were added in $60 \mathrm{~mL}$ of methanol $(\mathrm{MeOH})$ at room temperature. The mixture was transferred into the $100 \mathrm{ml}$ Teflon-lined stainless steel autoclave after the powder was dissolved, heated under $160{ }^{\circ} \mathrm{C}$ for $10 \mathrm{~h}$. After cooled to room temperature, the white precipitate was collected by centrifugation $(8000 \mathrm{rpm}, 6 \mathrm{~min})$, washed with $\mathrm{MeOH}$, and dried in a vacuum oven $\left(60^{\circ} \mathrm{C}, 12 \mathrm{~h}\right) . \mathrm{Bi}-\mathrm{MOF}-1$ was obtained by drying the powder at $150^{\circ} \mathrm{Cunder}$ vacumm to eliminate most of the coordinated water 
molecules. Bi-MOF-2 was obtained by the same procedure but replacing the reaction solvent $(\mathrm{MeOH})$ with a mixture of $\mathrm{DMF} / \mathrm{MeOH}(60 \mathrm{~mL}, 4: 1$ by volume).

Synthesis of Bi-MOF-3. $100 \mathrm{mg}$ of Bi-MOF-1 and $200 \mathrm{mg}$ L-Cysteine were dispersed in $40 \mathrm{~mL}$ of anhydrous $\mathrm{MeOH}$ followed by sonication and vigorous stirring for $8 \mathrm{~h}$. The obtained precipitate was collected by centrifugation ( $8000 \mathrm{rpm}, 6 \mathrm{~min}$ ), washed with $\mathrm{MeOH}$, and drying in a vacuum oven $\left(150^{\circ} \mathrm{C}, 12 \mathrm{~h}\right)$ to obtained Bi-MOF-3.

Synthesis of Bi-MOFs/rGO@PP separator. The Bi-MOFs/rGO@PP separator was fabricated by depositing the mixture of the Bi-MOFs and rGO onto one side of a commercial PP Celgard separator through a vacuum-assisted self-assembly method. Typically, $0.4 \mathrm{~mL}$ dispersion of $\mathrm{rGO}$ in ethanol $\left(1 \mathrm{mg} \mathrm{mL}^{-1}\right)$ and $24 \mathrm{~mL}$ dispersion of Bi-MOFs in ethanol $\left(0.05 \mathrm{mg} \mathrm{mL}^{-1}\right)$ were added into $25 \mathrm{~mL}$ ethanol solution and ultrasonicated for $30 \mathrm{~min}$ to form a homogeneous dispersion. Then the suspension of the Bi-MOFs and rGO were deposited onto the PP Celgard separator via vacuum filtration. The Bi-MOFs/rGO@PP separators were dried at room temperature for $12 \mathrm{~h}$ and further dried under vacuum at $60^{\circ} \mathrm{C}$ for $12 \mathrm{~h}$. Subsequently, the Bi-MOFs/rGO@PP separators were cut into circular disks of $16 \mathrm{~mm}$ in diameter, and the loading of BiMOFs/rGO was approximately $0.30 \mathrm{mg} \mathrm{cm}^{-2}$. The rGO@PP separators were fabricated using the same method but without Bi-MOFs. And the Bi-MOFs/rGO was prepared through evaporating the ethanol solvent in the Bi-MOFs/rGO dispersion.

Synthesis of CNT@S cathode. The CNT@S cathode was obtained by a simple melting-diffusion method. The CNTs were milled with sulfur together uniformly with 
a mass radio of $1: 3$ and heated at $155^{\circ} \mathrm{C}$ for $12 \mathrm{~h}$ in an airtight Teflon-lined stainless steel autoclave.

Material Characterization. The phase constituents were determined by XRD (Rigaku SmartLab $9 \mathrm{~kW}$ ). The surface morphology was characterized using a SEM (Thermofisher Apreo C), and XPS analysis (ThermoFisher Escalab 250Xi) was performed analyze the elemental composition and content. The sulfur content in the active electrode material (CNT@S) was tested by TGA thermogravimetric analyzer system. The UV-vis absorption spectra of polysulfides were measured by a spectrophotometer (UV-2600). The Raman spectra were collected using a Raman microscope (Renishaw inVia Qontor) system.

Electrochemical Measurements. The coin cells (CR2025) were assembled by using lithium foil as the anode, Bi-MOFs/rGO@PP as the separator, and 1 M LiTFSI in 1,3dioxolane (DOL)/dimethoxyethane (DME) (volume ratio of 1:1) as the electrolyte with $1 \mathrm{wt} \% \mathrm{LiNO}_{3}$ electrolyte additive. The amount of the electrolyte was controlled to 8$12 \mu 1 \mathrm{mg}^{-1}$ sulfur. The interlayers were placed between sulfur cathodes and PP separators. The cathode was prepared by pasting a sulfur slurry using Nmethylpyrrolidone as solvent (80wt \% CNT@S, 10 wt \% CNTs, and 10 wt \% PVDF binder) onto aluminum foil, which was vacuum-dried at $60{ }^{\circ} \mathrm{C}$ for $12 \mathrm{~h}$. The sulfur loading is around $1.5 \mathrm{mg} \mathrm{cm}^{-2} . \mathrm{CV}$ curves were recorded on an electrochemical workstation at a scanning rate of $0.1 \mathrm{mV} \mathrm{s}^{-1}$ in the range between 2.8 and $1.5 \mathrm{~V}$ at room temperature. The galvanostatic discharge-charge cycle tests and rate tests were carried out on a Neware battery testing system at current densities of $0.2-3 \mathrm{C}(1 \mathrm{C}=1675 \mathrm{~mA}$ 
$\left.\mathrm{g}^{-1}\right)$ with a cutoff voltage of $2.8-1.5 \mathrm{~V}$ vs. $\mathrm{Li} / \mathrm{Li}^{+}$at room temperature. The specific capacity was calculated based on the mass of sulfur. Electrochemical impedance spectroscopy was measured in the charged state at $2.8 \mathrm{~V}$. The voltage amplitude applied to the coin cells was $5 \mathrm{mV}$, with the frequency range from $100 \mathrm{kHz}$ to $1 \mathrm{~Hz}$.

Symmetrical Cell Assembly and Measurements. Symmetric cells were assembled by two identical electrodes (Bi-MOFs, $\mathrm{rGO}$ ) with $20 \mu \mathrm{L}$ of $\mathrm{Li}_{2} \mathrm{~S}_{6}$ electrolyte. The $\mathrm{Li}_{2} \mathrm{~S}_{6}$ solution was prepared by adding $\mathrm{S}$ and $\mathrm{Li}_{2} \mathrm{~S}$ powders at a molar ratio of 5:1 into a DOL/DME solution (1:1 by volume) and stirred for $24 \mathrm{~h}$ under $60^{\circ} \mathrm{C} . \mathrm{CV}$ was carried out in the voltage range from -0.7 to $0.7 \mathrm{~V}$ at a scan rate of $10 \mathrm{mV} \mathrm{s}^{-1}$.

$\mathbf{L i}_{2} \mathbf{S}$ Nucleation Experiments. Sulfur and $\mathrm{Li}_{2} \mathrm{~S}$ were stirred in a molar ratio of 7:1 in tetraglyme solvent for $24 \mathrm{~h}$ to obtain the $\mathrm{Li}_{2} \mathrm{~S}_{8}$ solution $\left(0.2 \mathrm{~mol} \mathrm{~L} \mathrm{~L}^{-1}\right)$. BiMOF/rGO@CP, rGO@CP, and CP were used as collectors. $25 \mu \mathrm{L}$ of $\mathrm{Li}_{2} \mathrm{~S}_{8}$ solution was deposited onto the working electrode, and then $25 \mu \mathrm{L}$ of LiTFSI $\left(1.0 \mathrm{~mol} \mathrm{~L}^{-1}\right)$ without $\mathrm{Li}_{2} \mathrm{~S}_{8}$ was dropped onto the lithium anode. The batteries were discharged at $0.112 \mathrm{~mA}$ to $2.06 \mathrm{~V}$ and then kept potentiostatically at $2.05 \mathrm{~V}$ for $\mathrm{Li}_{2} \mathrm{~S}$ to nucleate and grow until the current fell below $10^{-5} \mathrm{~A}$. The nucleation rate of $\mathrm{Li}_{2} \mathrm{~S}$ on the substrates was calculated based on Faraday's law.

Shuttle test. The $5 \times 10^{-4} \mathrm{M} \mathrm{Li}_{2} \mathrm{~S}_{6}$ solution was prepared by reacting sulfur and $\mathrm{Li}_{2} \mathrm{~S}$ at a molar ratio of 5:1, which added to precise configured liquid mixture of 1, 2dimethoxyethane (DME) and 1, 3-dioxolane (DOL) (1:1 in volume) and homogenized by vigorous stirring at $70{ }^{\circ} \mathrm{C}$ for 48 hours. Then, The same volume of $5 \times 10^{-3} \mathrm{M} \mathrm{Li}_{2} \mathrm{~S}_{6}$ 
solution and blank solution were added to the two sides of the proton exchanger container, sealed and tested.

Visualized adsorption test. A $5 \times 10^{-4} \mathrm{M} \mathrm{Li}_{2} \mathrm{~S}_{6}$ solution was prepared by adding sulfur and $\mathrm{Li}_{2} \mathrm{~S}$ at a molar ratio of 1:3 in 1, 2-dimethoxymethane/1,3-dioxolane (DME/DOL) (1:1 by volume) solvent followed by vigorous magnetic stirring at room temperature until the solid dissolved into a uniform solution. $10 \mathrm{mg}$ of Bi-MOFs and rGO powders were added into $3 \mathrm{~mL}$ of solution, respectively, and aged to observe the color of the solution. These suspensions were left for UV analysis.

In-situ Raman spectroscopy analysis. A Li-S battery consistent with the button battery was assembled in in-situ Raman device (provided by Beijing Science Star technology Co., Ltd. China). The battery was continuously charged/discharged at current rate of $0.2 \mathrm{C}$ during the whole Raman spectrum collection process. The Raman spectrum was simultaneously recorded every $10 \mathrm{~min}$.

In-situ UV-vis absorption spectra. In situ UV-vis spectroscopic measurements were performed on a spectrophotometer (UV-2600). The spectroelectrochemical cell used in the present study is described in our previous work. ${ }^{2}$ The Bi-MOF-1 or rGOcoated glassy carbon electrode as cathode, platinum wire as anode. $0.5 \mathrm{M} \mathrm{Li}_{2} \mathrm{~S}_{8}$ in dimethyl sulfoxide was used as the electrolyte. During the tests, the potential was controlled using an electrochemical workstation (Autolab M204). Here, the UV-vis absorbance was normalized by making the absorbance at $2.8 \mathrm{~V}$ as 1 .

Computation. The present first principle DFT calculations are performed with the projector augmented wave (PAW) method. ${ }^{3}$ The exchange-functional is treated using 
the generalized gradient approximation (GGA) of Perdew-Burke-Ernzerhof (PBE) ${ }^{4}$ functional. The cut-off energy of the plane-wave basis is set at $400 \mathrm{eV}$ for optimizing calculations of atoms and cell optimization. The vacuum spacing in a direction perpendicular to the plane of the catalyst is $15 \AA$ for rGO. The Brillouin zone integration is performed using $2 \times 2 \times 1$ Monkhorst-Pack k-point sampling for a primitive cell. ${ }^{5}$ The self-consistent calculations apply a convergence energy threshold of $10^{-5} \mathrm{eV}$. The equilibrium lattice constants are optimized with maximum stress on each atom within $0.05 \mathrm{eV} \AA^{-1}$. For Bi-MOF-1, we choose the unit of Bi-MOF-1 structures to calculations the properties. What's more, $\mathrm{Li}_{2} \mathrm{~S}$ and $\mathrm{Li}$ ions decomposition and migration barrier energies had been evaluated using the climbing nudged elastic band methods.

The free energy was calculated using the equation:

$$
G=E+Z P E-T S
$$

where $G, E, Z P E$ and $T S$ are the free energy, total energy from DFT calculations, zero point energy and entropic contributions, respectively.

The adsorption energy is defined as:

$$
\mathrm{E}_{a d}=\mathrm{E}_{\text {total }}-\mathrm{E}_{\text {subs }}-\mathrm{E}_{\text {mole }}
$$

where $E_{\text {total }}, E_{\text {subs }}$, and $E_{\text {mole }}$ denote the total energy of substrate with adsorbate, substrate, and free molecule, respectively. 


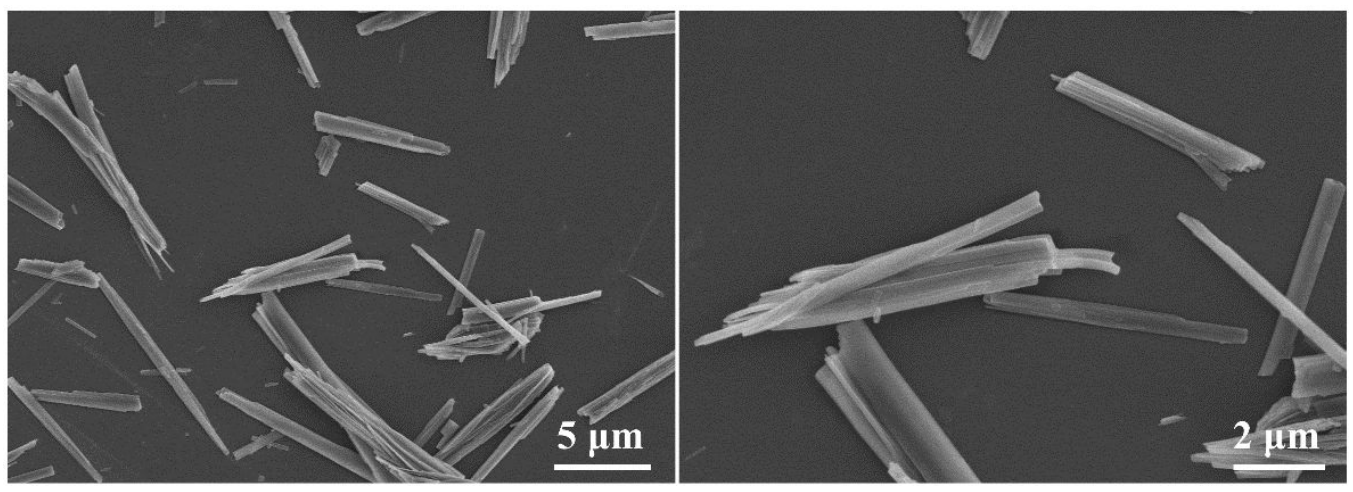

Figure S1. SEM images of the synthesized Bi-MOF-1.
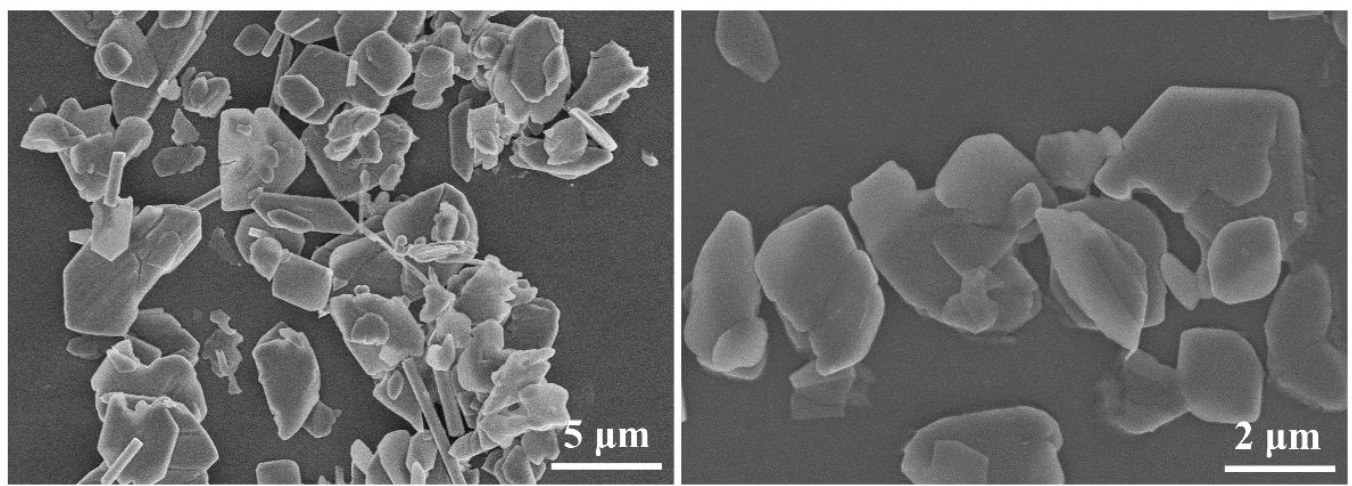

Figure S2. SEM images of the synthesized Bi-MOF-2.

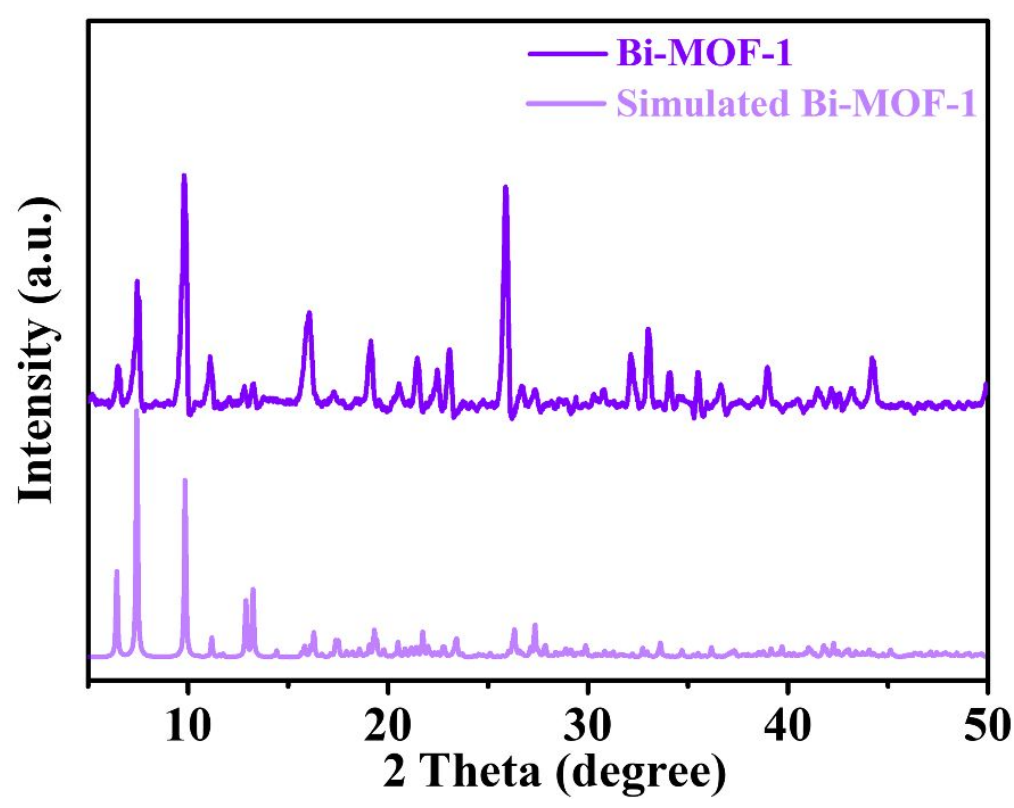

Figure S3. PXRD patterns of Bi-MOF-1. 




Figure S4. PXRD patterns of Bi-MOF-2.

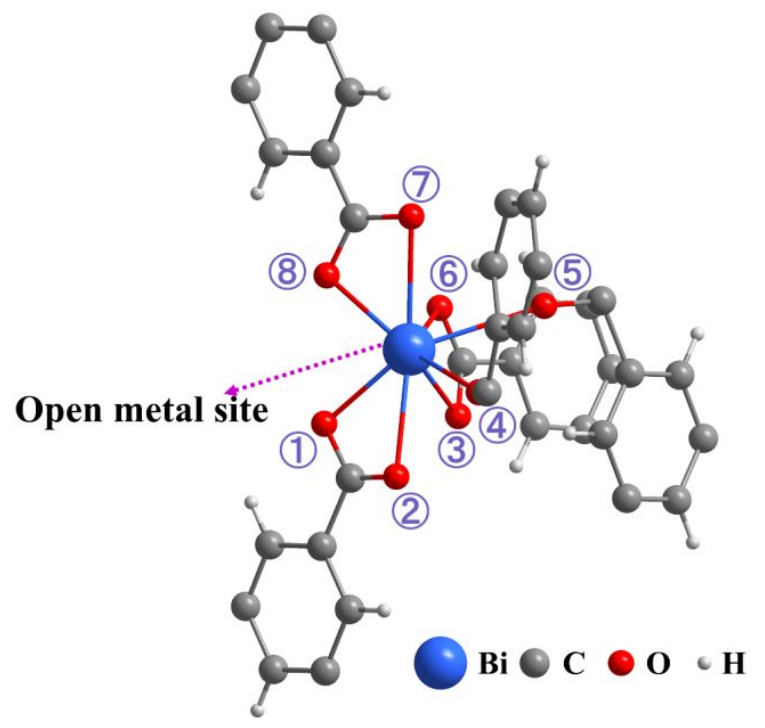

Figure S5. The crystal structure of Bi-MOF-1. 


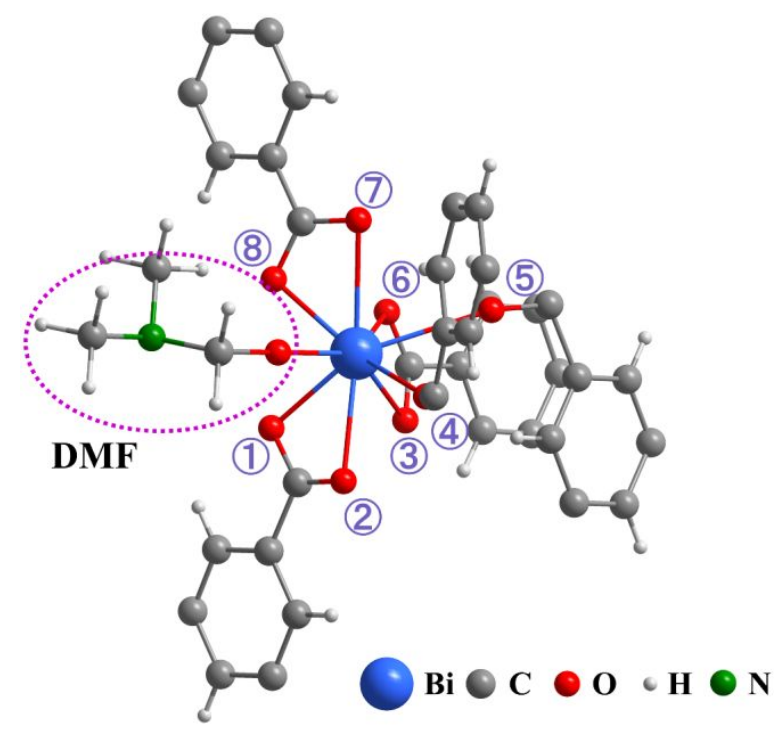

Figure S6. The crystal structure of Bi-MOF-2.
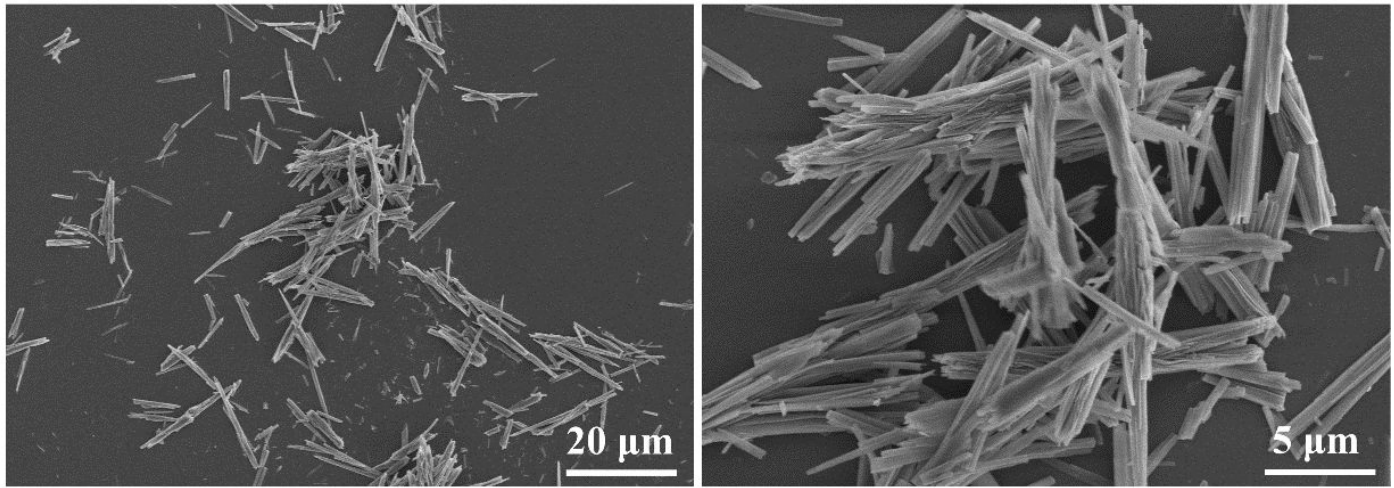

Figure S7. SEM images of the synthesized Bi-MOF-3.

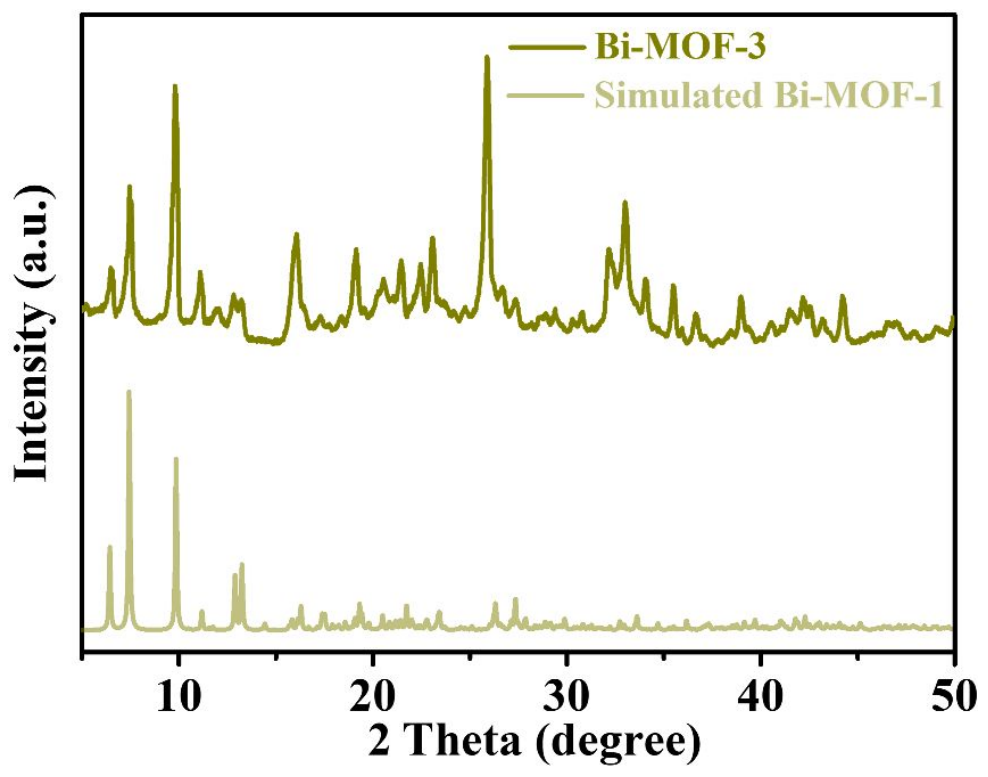

Figure S8. PXRD patterns of Bi-MOF-3. 


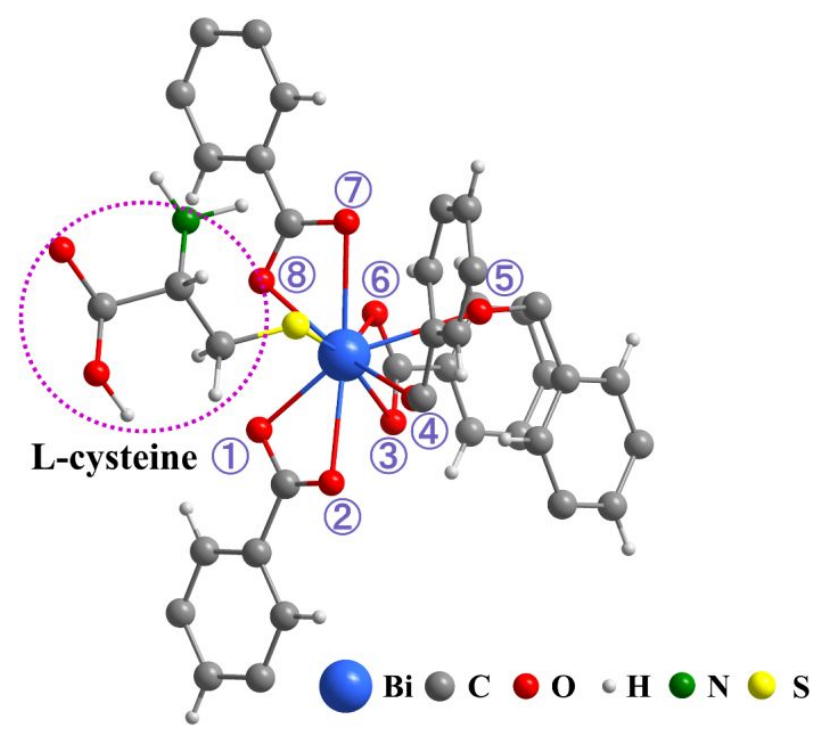

Figure S9. The crystal structure of Bi-MOF-3.
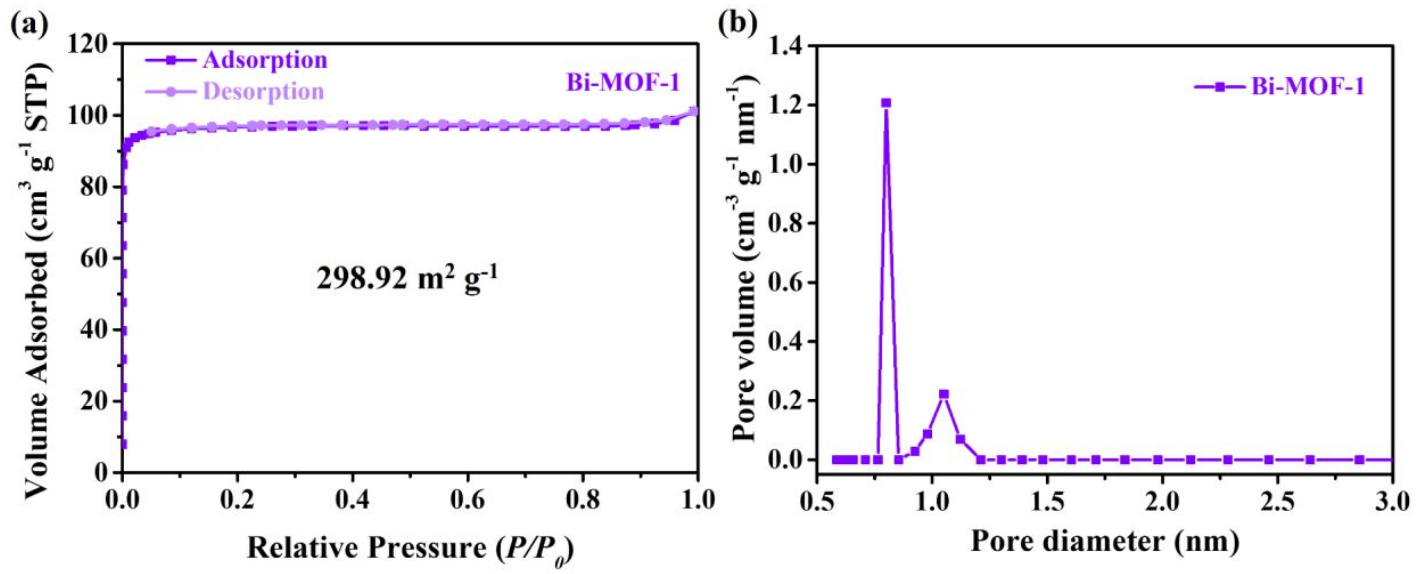

Figure S10. $\mathrm{N}_{2}$ adsorption/desorption isotherms of Bi-MOF-1.

(a)

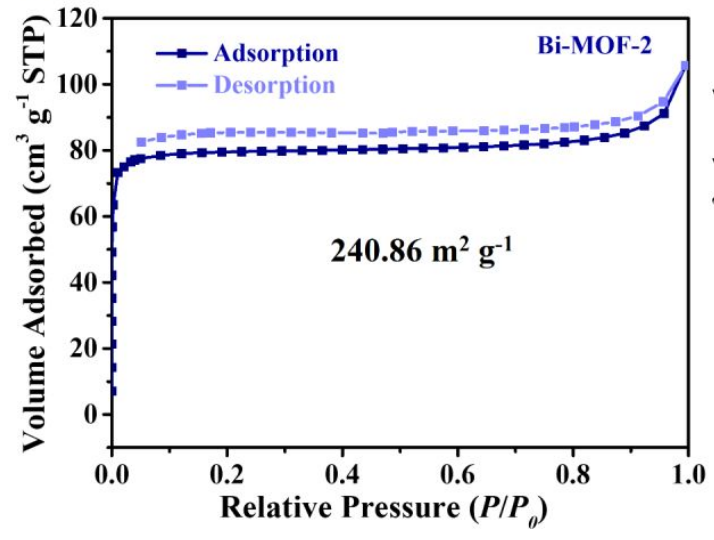

(b)

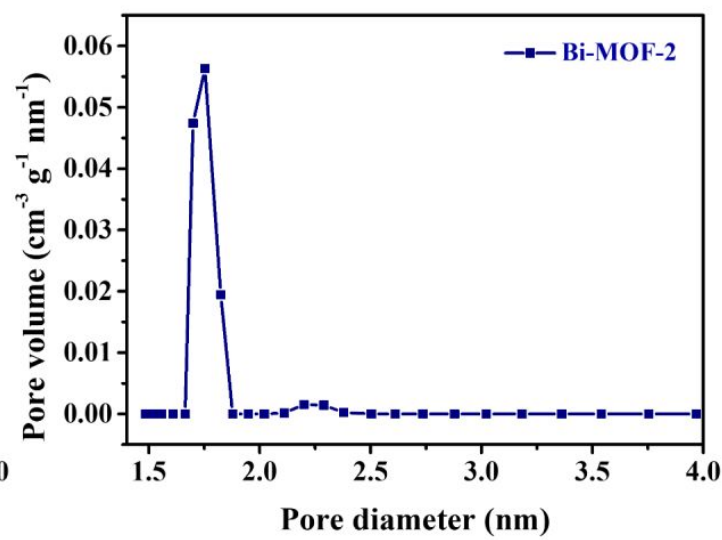

Figure S11. $\mathrm{N}_{2}$ adsorption/desorption isotherms of Bi-MOF-2. 
(a)

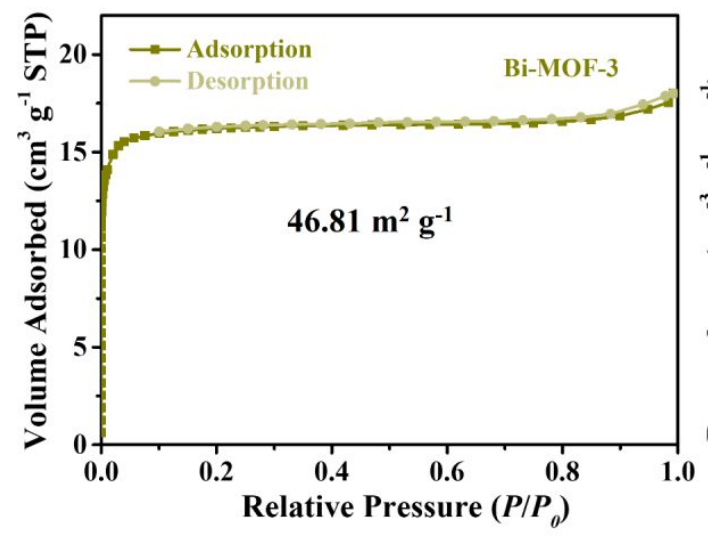

(b)

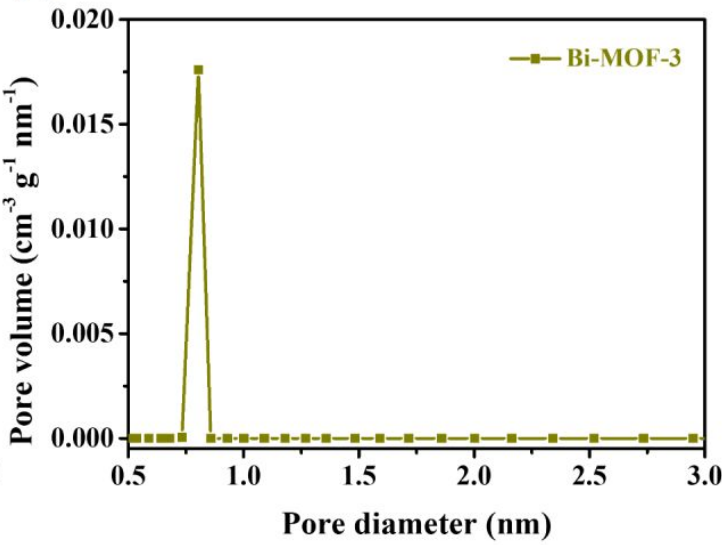

Figure $\mathrm{S} 12 . \mathrm{N}_{2}$ adsorption/desorption isotherms of Bi-MOF-3.
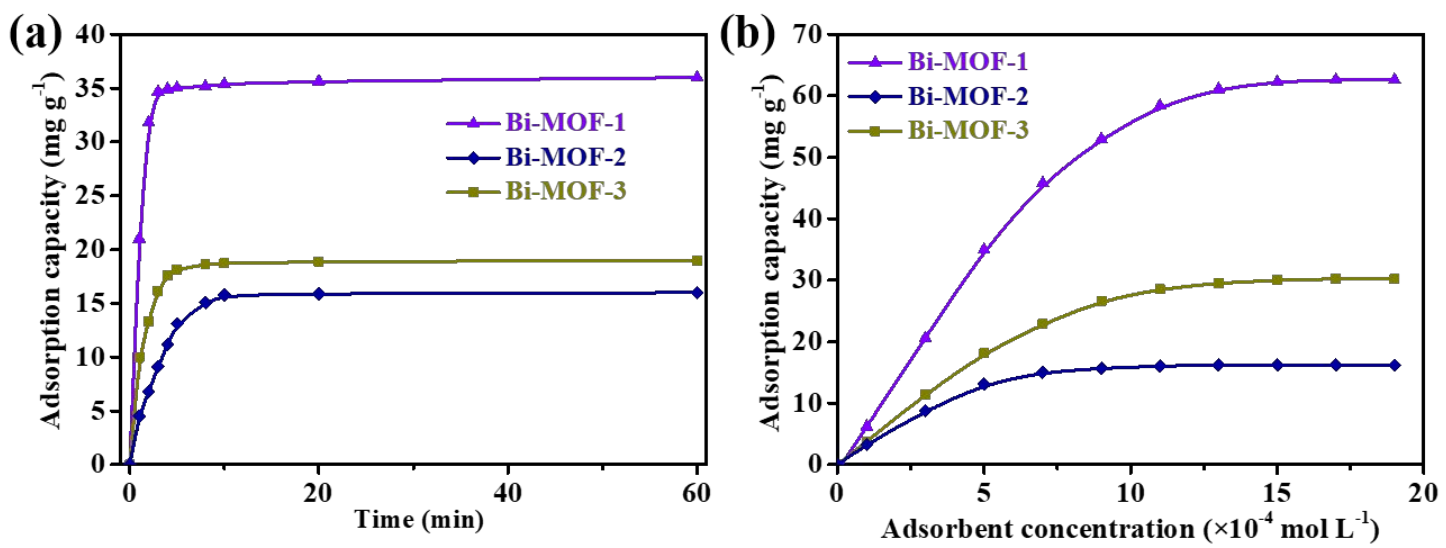

Figure S13. The adsorption kinetics (a) and saturate adsorption capacities (b) of BiMOFs for $\mathrm{Li}_{2} \mathrm{~S}_{6}$.

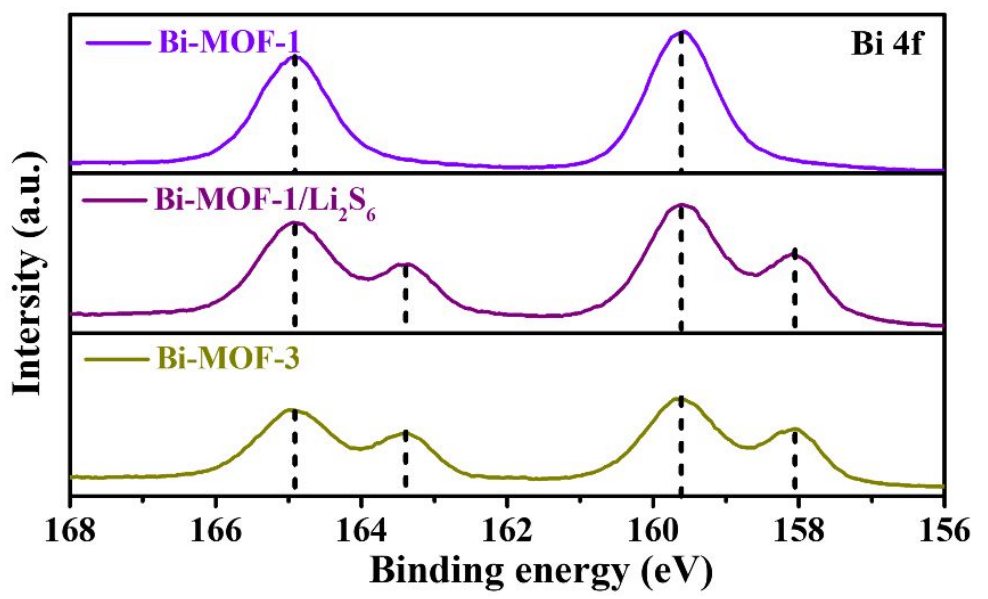

Figure S14. Bi 4f XPS spectra of Bi-MOF-1, Bi-MOF-1/Li $\mathrm{S}_{6}$ and Bi-MOF-3. 


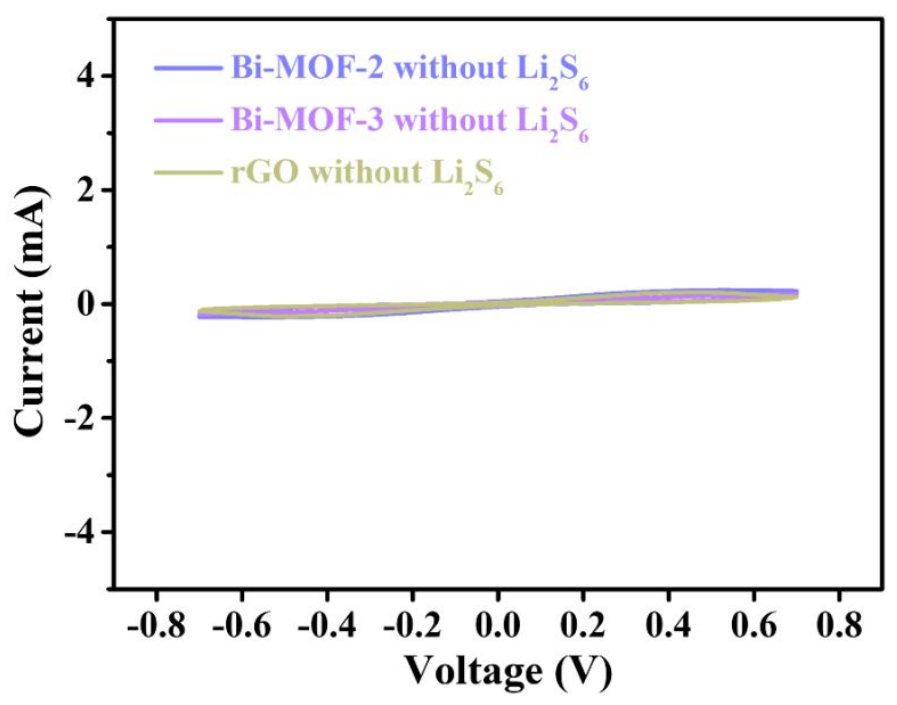

Figure S15. CV curves of symmetrical cells with electrodes coated with rGO and different Bi-MOFs without $\mathrm{Li}_{2} \mathrm{~S}_{6}$.

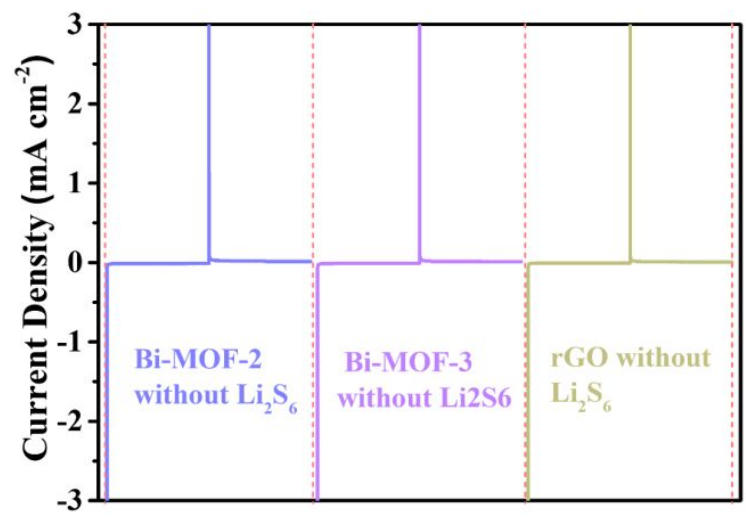

Figure S16. Chronoamperometry curves of symmetrical cells with electrodes coated with rGO and different Bi-MOFs without $\mathrm{Li}_{2} \mathrm{~S}_{6}$.

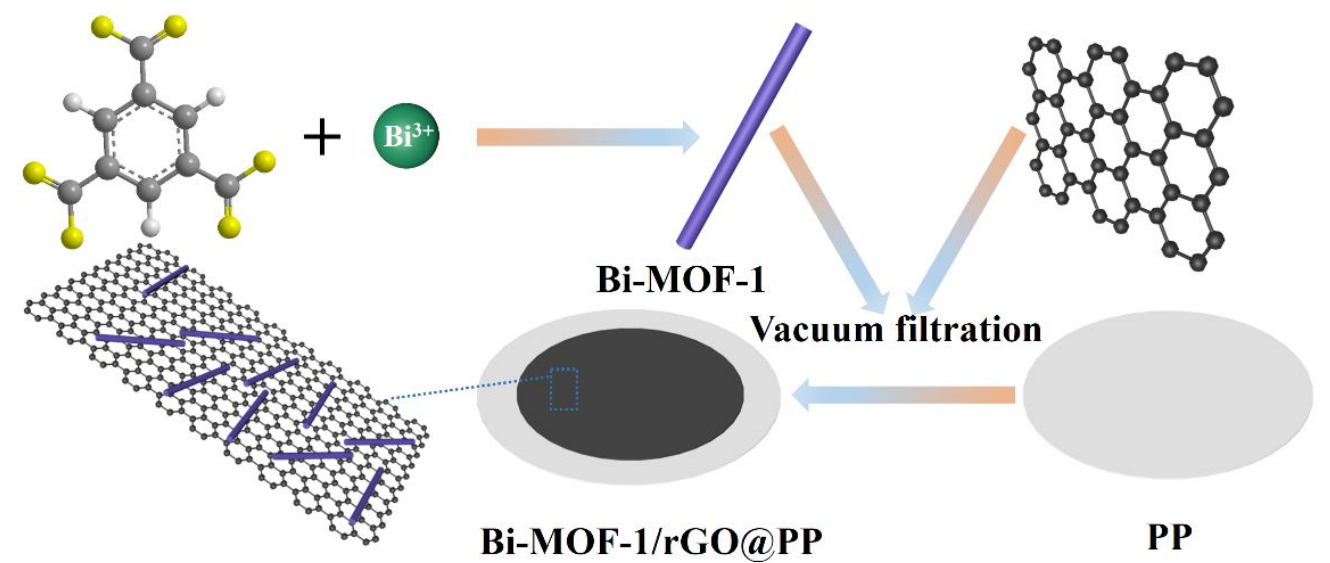

Figure S17. Fabrication procedure for the Bi-MOF-1/rGO@PP separator. 


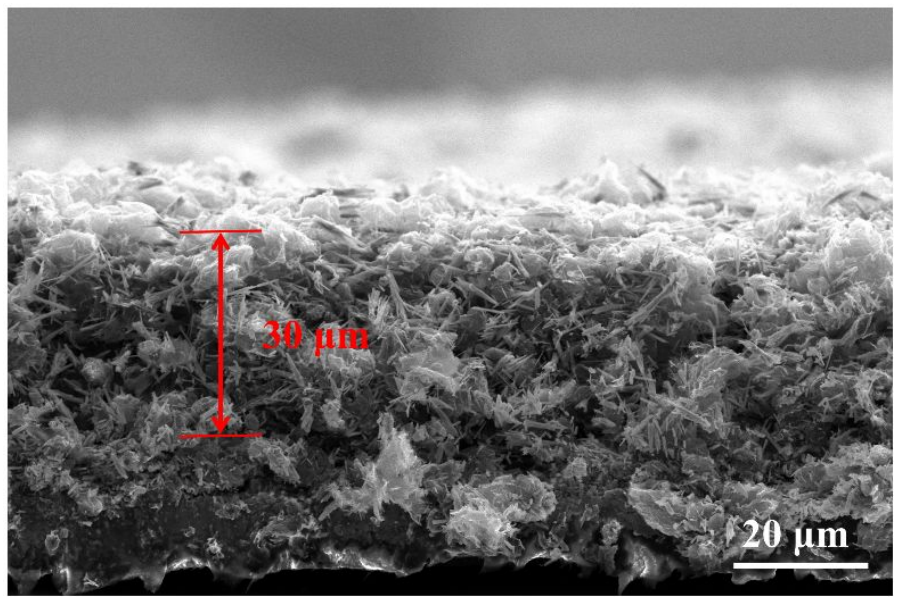

Figure S18. Cross-sectional SEM image of Bi-MOF-1/rGO@PP.
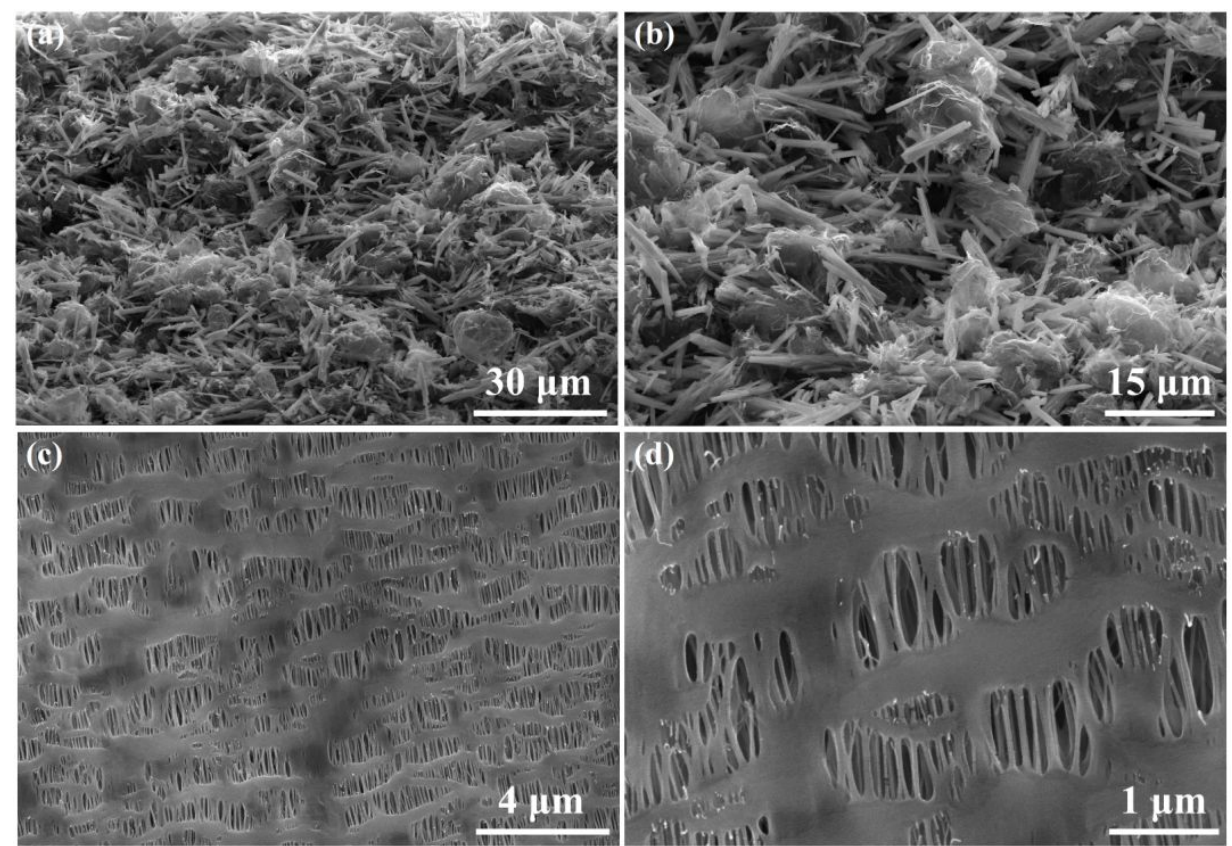

Figure S19. (a), (b) SEM images of Bi-MOF-1/rGO@PP. (c), (d) SEM images of PP.

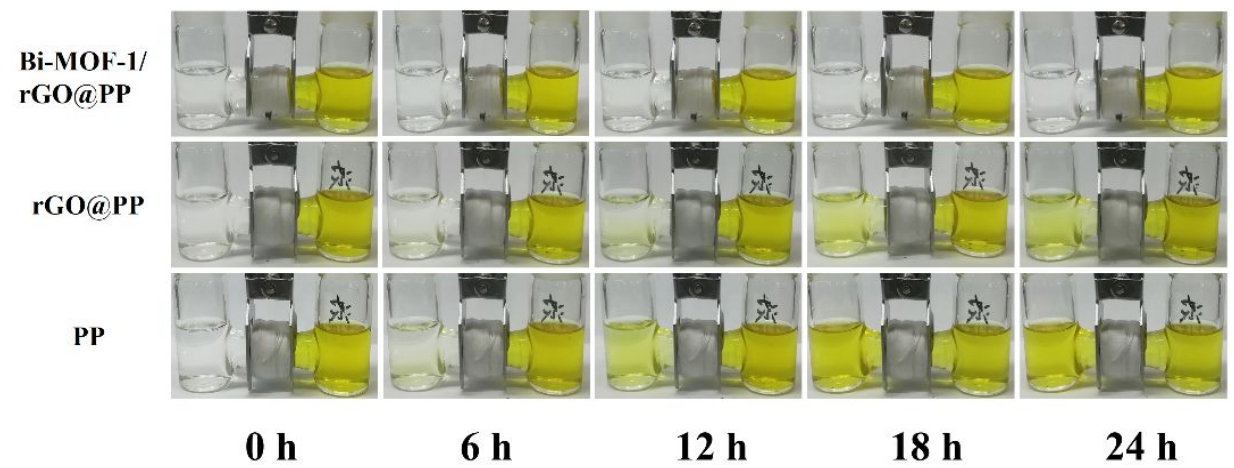

Figure S20. Permeation experiment with the H-type cell for the Bi-MOF-1/rGO@PP, rGO@PP and PP separators. 


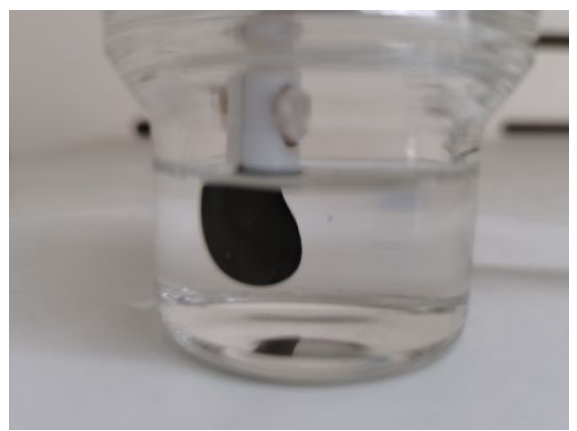

Figure S21. The separator functionalized with the Bi-MOF-1/rGO interlayer after being immersed in the electrolyte for three days.

(a)

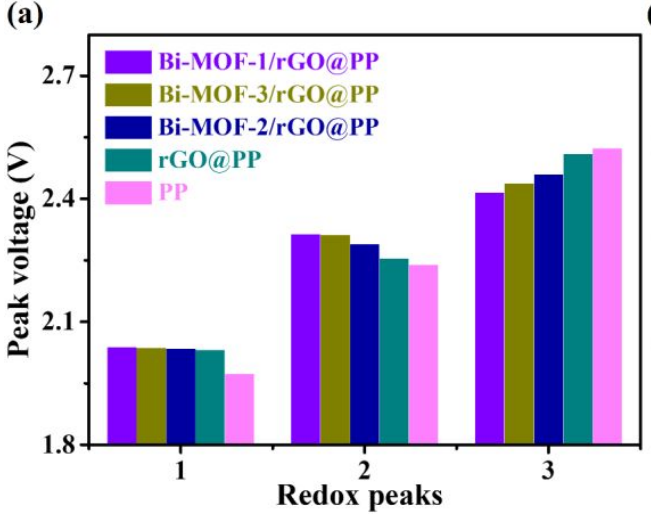

(b)

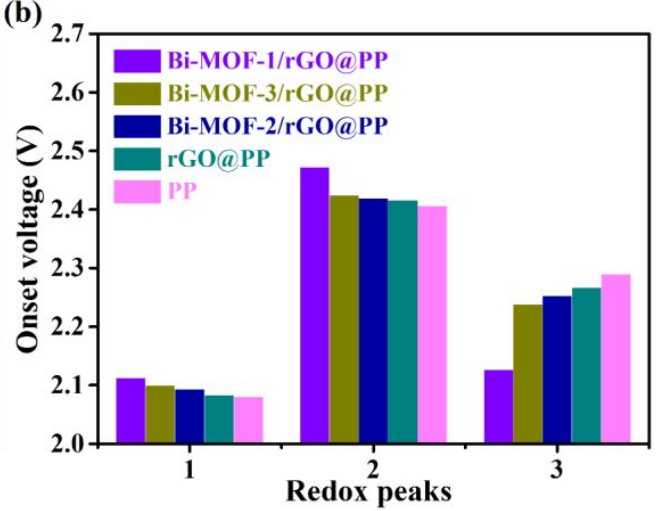

Figure S22. The peak voltages (a) and onset voltages (b) of Bi-MOFs/rGO@PP, rGO@PP and PP separators calculated from the CV curves in Figure 2f.

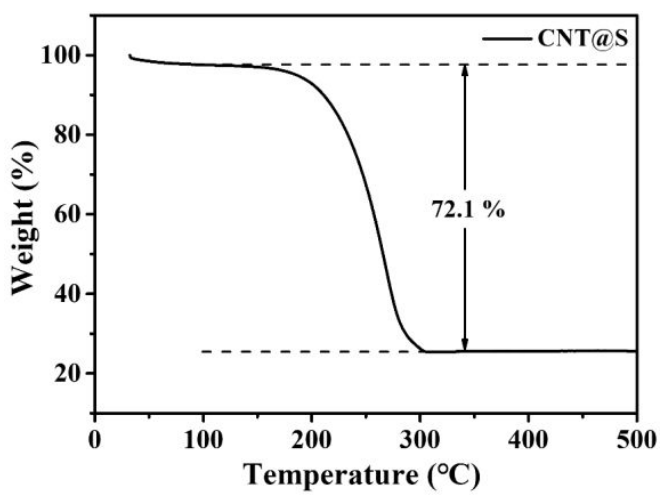

Figure S23. Thermogravimetric (TGA) analysis of CNT@S cathode with the sulfur loading of $72.1 \%$ 


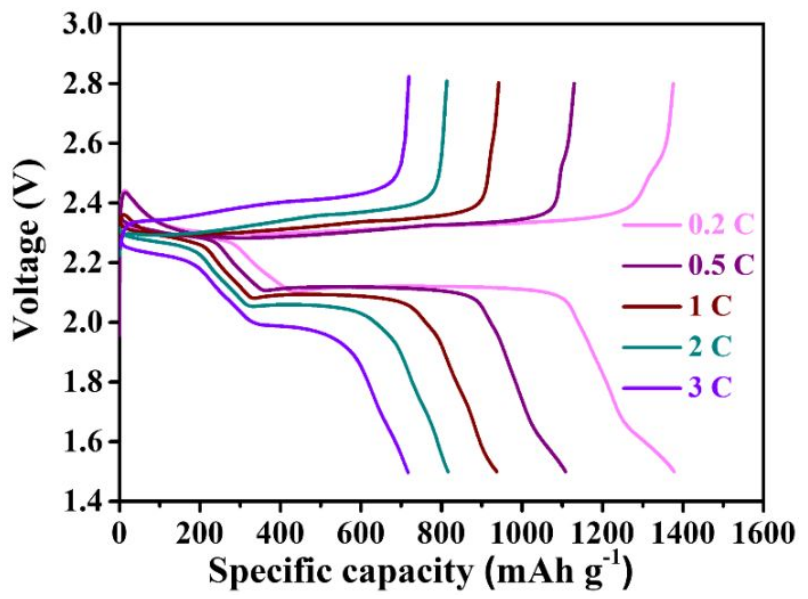

Figure S24. Galvanostatic charge-discharge curves of Bi-MOF-1/rGO@PP at 0.2-3 C.

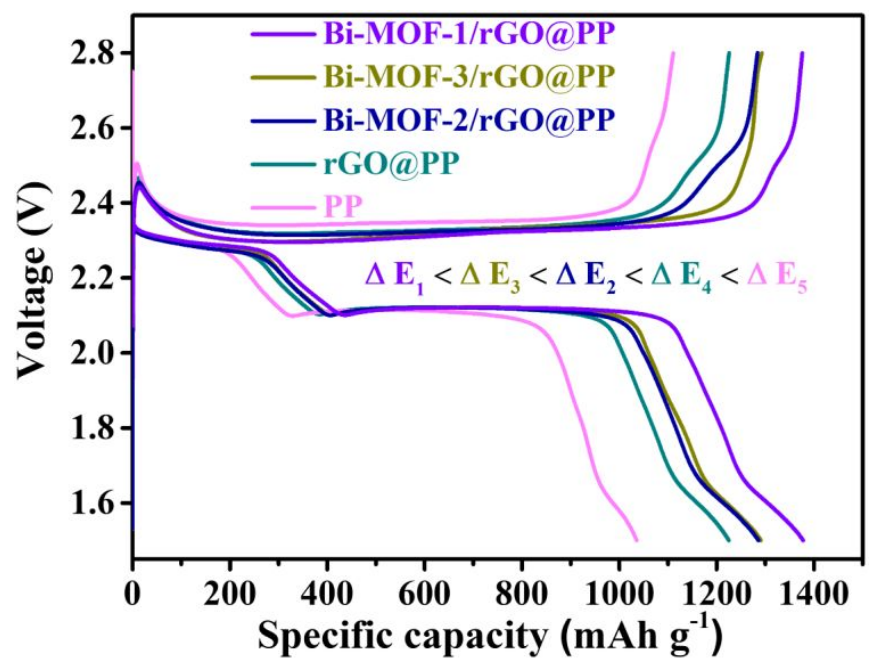

Figure S25. Galvanostatic charge-discharge curves at $0.2 \mathrm{C}$ of LSBs with BiMOFs/rGO@PP,rGO@PP and PP separators.

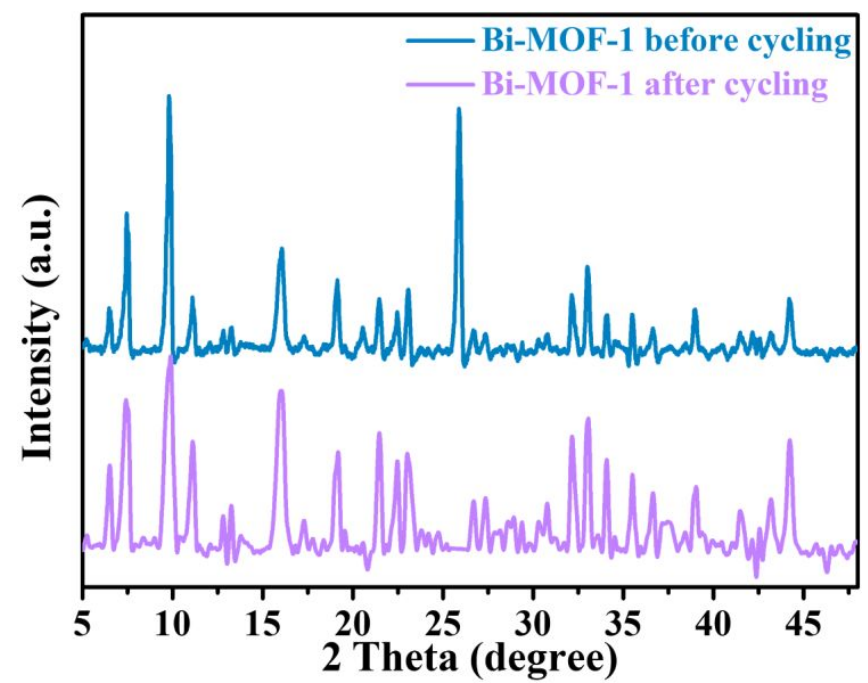

Figure S26. PXRD patterns of Bi-MOF-1/rGO before and after cycling. 

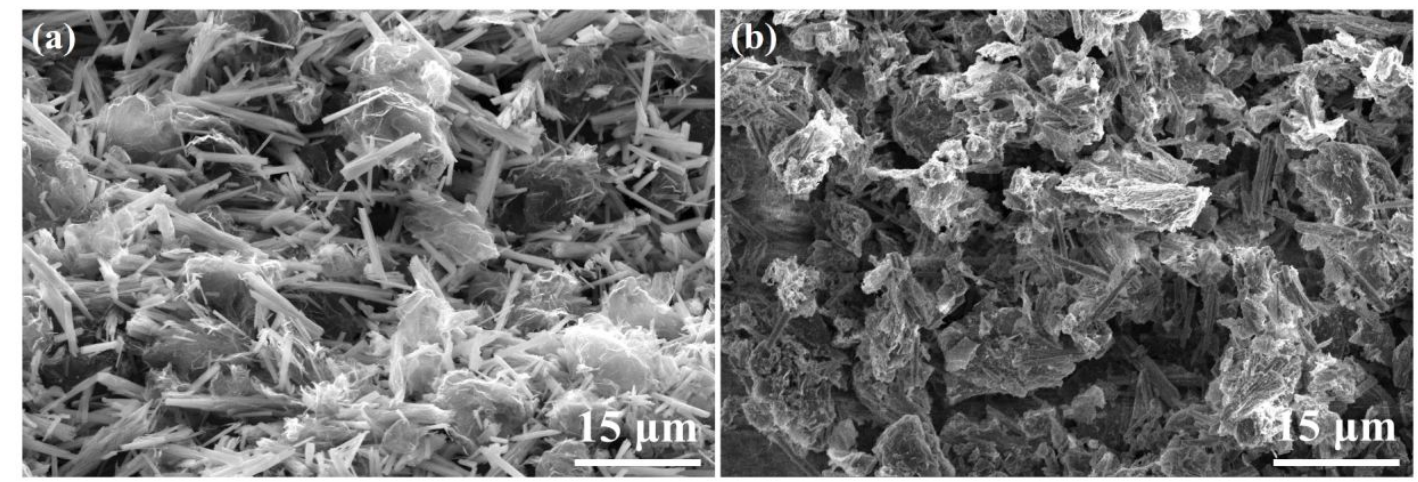

Figure S27. SEM images of Bi-MOF-1/rGO before (a) and after (b) cycling.

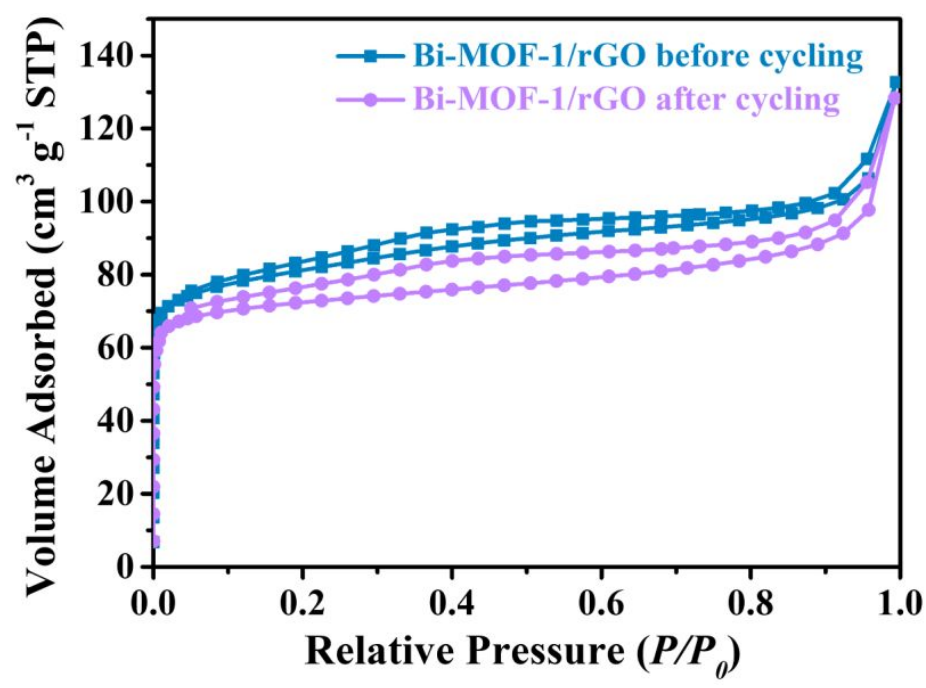

Figure S28. $\mathrm{N}_{2}$ adsorption/desorption isotherms of Bi-MOF-1/rGO before and after cycling.

(a)

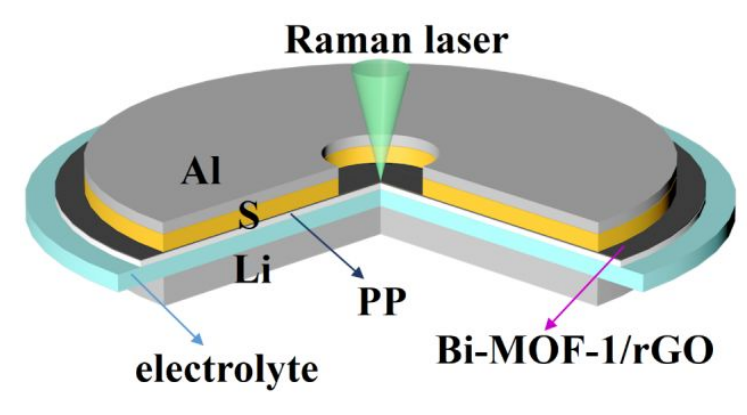

(b)



Figure S29. (a) Schematic diagram of the cross-section of the LSB with Bi-MOF1/rGO@PP separator fabricated in in-situ Raman device. (b) The first galvanostatic discharge-charge curve of LSB. 

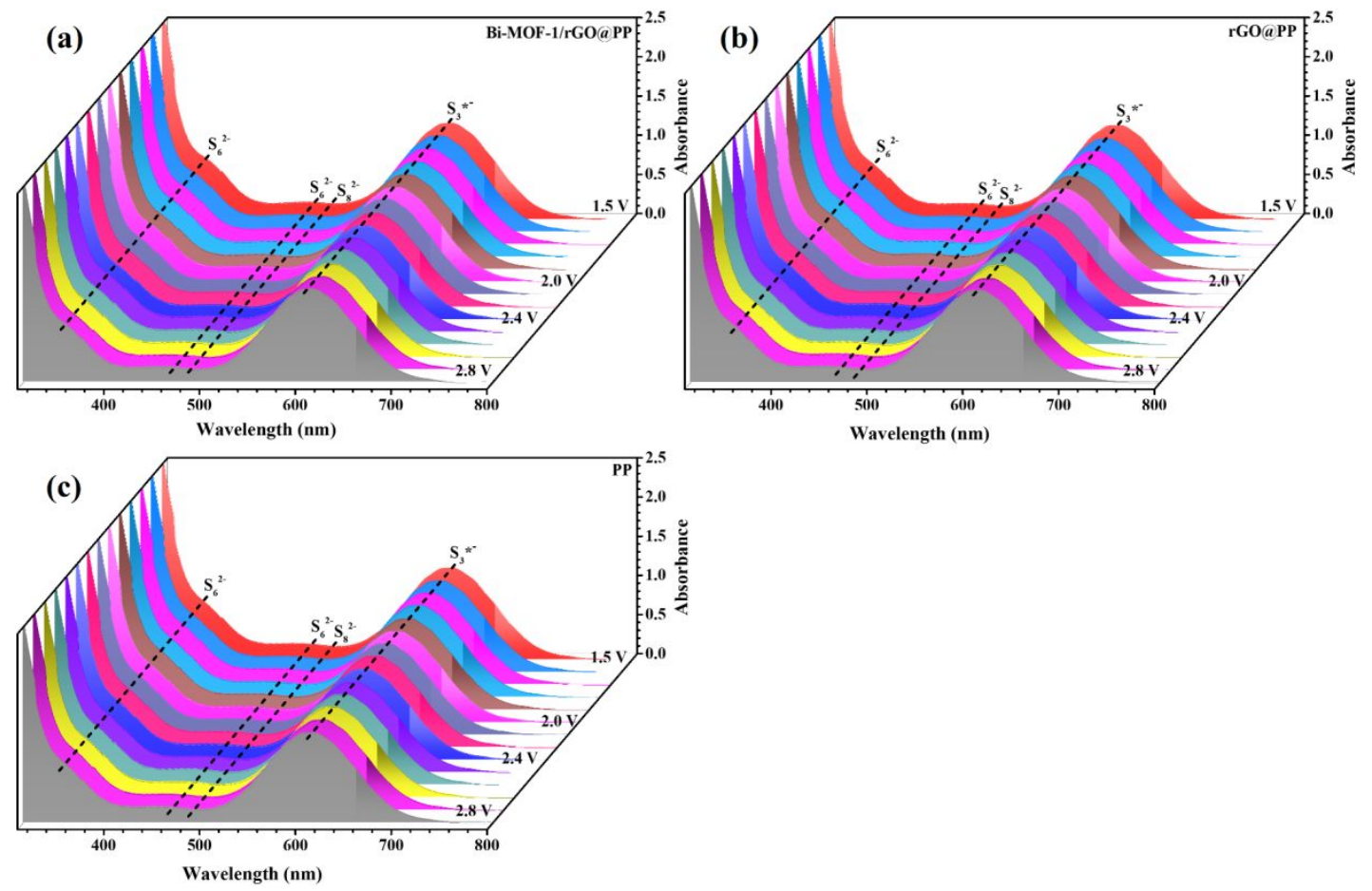

Figure $\mathrm{S} 30$. In situ $\mathrm{UV}$-vis spectra of $\mathrm{Li}_{2} \mathrm{~S}_{8}$ solution during discharge process with BiMOF-1/rGO@PP (a),rGO@PP (b) and PP (c) as electrodes.

(a)

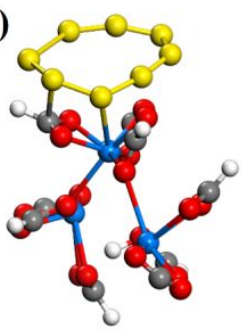

$\mathrm{S}_{8} *$

(d)

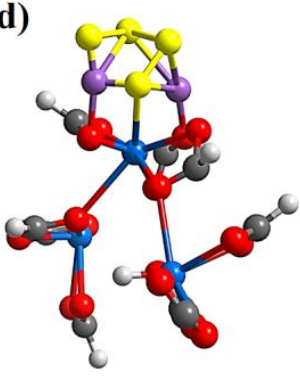

$\mathrm{Li}_{2} \mathrm{~S}_{4}{ }^{*}$ (b)

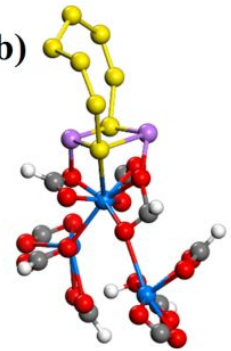

(e)

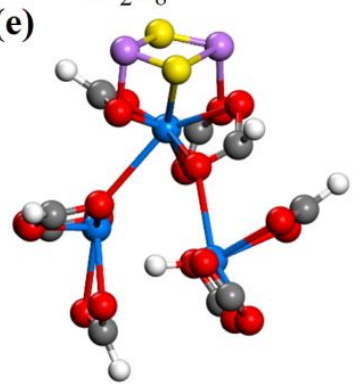

$\mathrm{Li}_{2} \mathrm{~S}_{2} *$ (c)

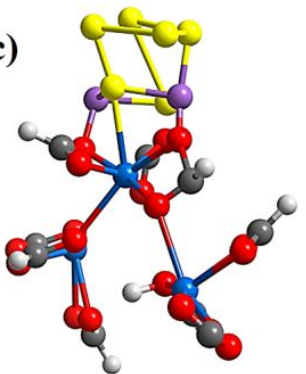

(f)

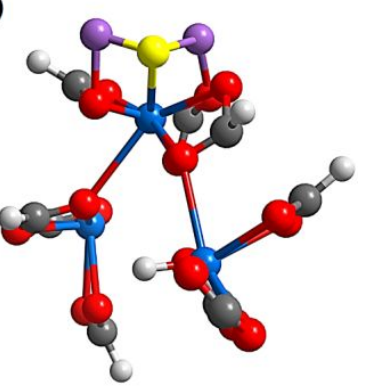

$\mathrm{Li}_{2} \mathrm{~S}^{*}$

Figure S31. Calculated adsorption energies between $\mathrm{S}_{8}(\mathrm{a}), \mathrm{Li}_{2} \mathrm{~S}_{8}(\mathrm{~b}), \mathrm{Li}_{2} \mathrm{~S}_{6}$ (c), $\mathrm{Li}_{2} \mathrm{~S}_{4}$ (d), $\mathrm{Li}_{2} \mathrm{~S}_{2}(\mathrm{e}), \mathrm{Li}_{2} \mathrm{~S}$ (f) and the $\mathrm{Bi}^{3+}$ clusters in Bi-MOF-1. 
(a)

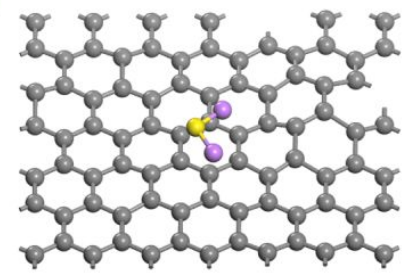

(d)

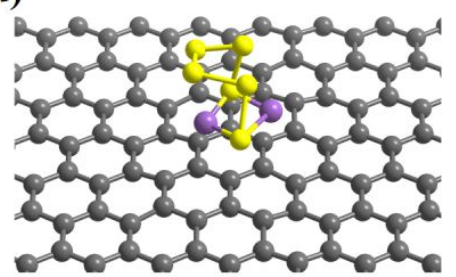

$\mathrm{Li}_{2} \mathrm{~S}_{6} *$ (b)

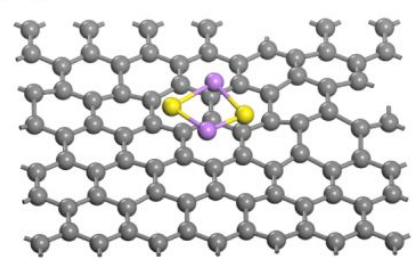

$\mathrm{Li}_{2} \mathrm{~S}_{2}$ *

(e)

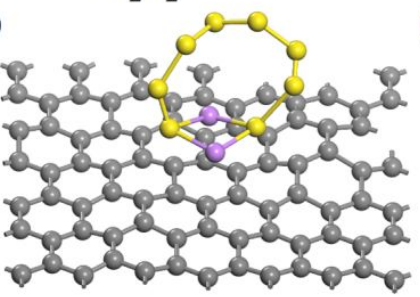

$\mathrm{Li}_{2} \mathrm{~S}_{8}$ * (c)

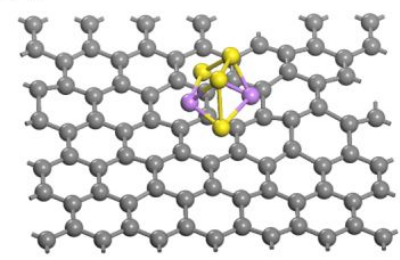

$\mathrm{Li}_{2} \mathrm{~S}_{4}$ *

(f)

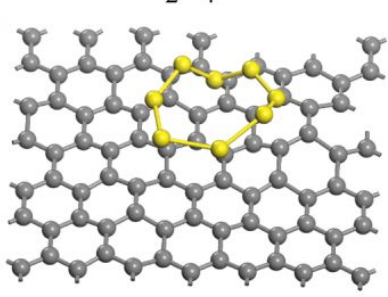

$\mathrm{S}_{8}$ *

Figure S32. Calculated adsorption energy between $\mathrm{Li}_{2} \mathrm{~S}$ (a), $\mathrm{Li}_{2} \mathrm{~S}_{2}(\mathrm{~b}), \mathrm{Li}_{2} \mathrm{~S}_{4}(\mathrm{c}), \mathrm{Li}_{2} \mathrm{~S}_{6}$

(d), $\mathrm{Li}_{2} \mathrm{~S}_{8}(\mathrm{e}), \mathrm{S}_{8}(\mathrm{f})$ and $\mathrm{rGO}$.

(a)

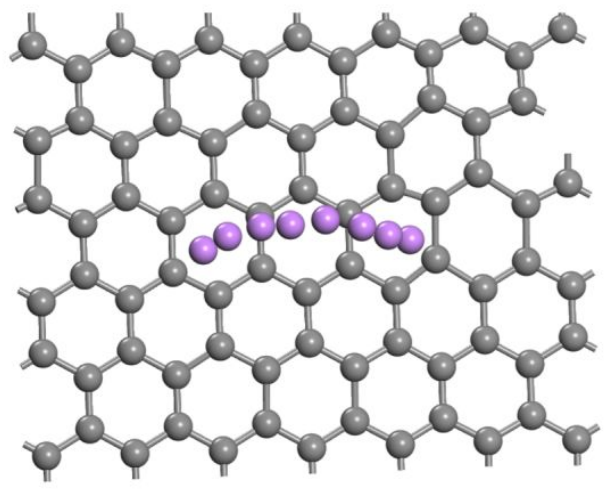

(b)

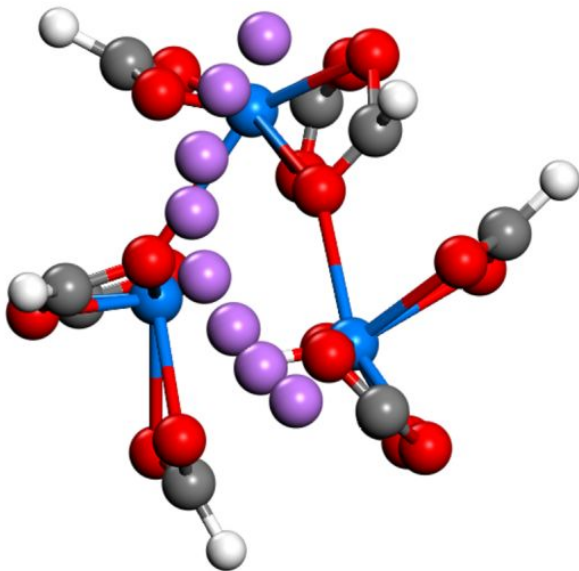

Figure $\mathrm{S} 33$. (a) $\mathrm{Li}^{+}$diffusion path on rGO. (b) $\mathrm{Li}^{+}$diffusion path on the $\mathrm{Bi}^{3+}$ clusters in Bi-MOF-1. 
(a)

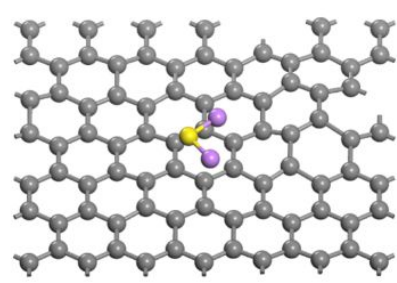

(b)

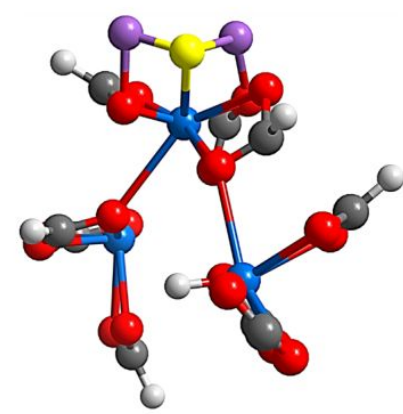

Inital $\left(\mathbf{L i}_{2} \mathbf{S}\right)$
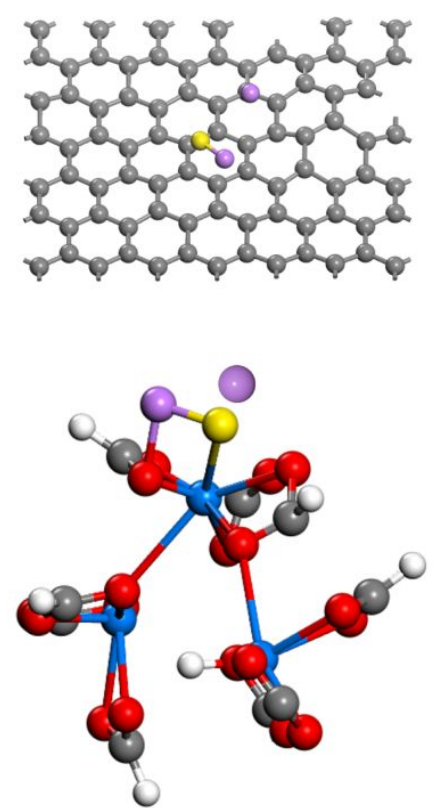

TS (LiS-Li)
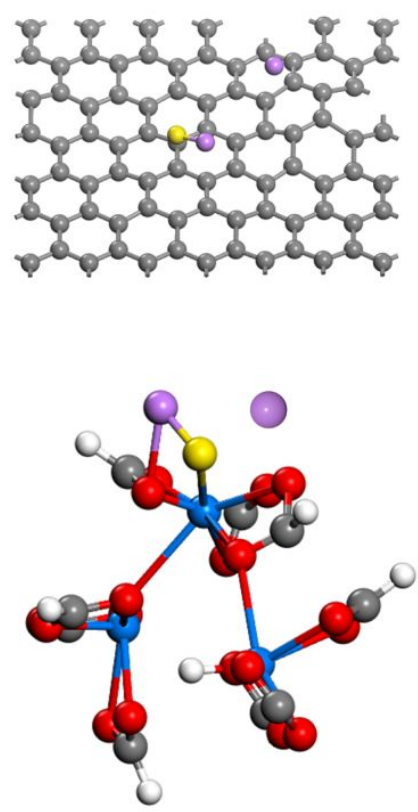

Final $(\mathbf{L i S}+\mathbf{L i})$

Figure S34. (a) $\mathrm{Li}_{2} \mathrm{~S}$ decomposition processes on $\mathrm{rGO}$. (b) $\mathrm{Li}_{2} \mathrm{~S}$ decomposition processes on the $\mathrm{Bi}^{3+}$ clusters in $\mathrm{Bi}-\mathrm{MOF}-1$. 
Table S1. Comparison of the key figures of merit of LSBs using our separator with other state-of-the-art separators.

\begin{tabular}{|c|c|c|c|c|c|}
\hline Catalysts & $\begin{array}{c}\text { Initial capacity } \\
\qquad\left[\mathrm{mA} \mathrm{h} \mathrm{g}^{-1}\right]\end{array}$ & $\begin{array}{l}\text { Cycle number } \\
\text { (retention) }\end{array}$ & Rate & $\begin{array}{c}\text { Decay } \\
\text { rate/cycle }\end{array}$ & Ref. \\
\hline $\begin{array}{l}\text { Activated expanded } \\
\text { graphite/chitosan }\end{array}$ & 1264 & $3000(37.0 \%)$ & $1 \mathrm{C}$ & $0.021 \%$ & 6 \\
\hline $\begin{array}{c}\text { Ultrathin } \\
\mathrm{MnO}_{2} / \mathrm{GO} / \mathrm{CNT}\end{array}$ & 1065 & $2500(27.5 \%)$ & $1 \mathrm{C}$ & $0.029 \%$ & 7 \\
\hline $\begin{array}{c}\mathrm{Co}_{9} \mathrm{~S}_{8} \text { nanowall } \\
\text { array }\end{array}$ & 869 & $1000(61 \%)$ & $1 \mathrm{C}$ & $0.039 \%$ & 8 \\
\hline $\begin{array}{l}\mathrm{rGO} / \text { sodium } \\
\text { lignosulfonate }\end{array}$ & 707 & $1000(74.0 \%)$ & $2 \mathrm{C}$ & $0.026 \%$ & 9 \\
\hline Fe-SACs & 1065 & $750(83.7 \%)$ & $0.5 \mathrm{C}$ & $0.022 \%$ & 10 \\
\hline $\mathrm{Fe}_{3} \mathrm{C} @ \mathrm{Fe}_{3} \mathrm{O}_{4} @ \mathrm{C}$ & 1600 & $50(62.5 \%)$ & $0.1 \mathrm{C}$ & $0.75 \%$ & 11 \\
\hline $\mathrm{SND}-\mathrm{Mo}_{2} \mathrm{~N}$ & 854 & $600(73 \%)$ & $1 \mathrm{C}$ & $0.045 \%$ & 12 \\
\hline $\mathrm{SA}-\mathrm{Fe} / \mathrm{Fe}_{2} \mathrm{~N} @ \mathrm{NG}$ & 951 & $500(84.1 \%)$ & $1 \mathrm{C}$ & $0.0318 \%$ & 13 \\
\hline VN@NG & 1003 & $200(70.3 \%)$ & $0.5 \mathrm{C}$ & $0.148 \%$ & 14 \\
\hline $\mathrm{Ce}-\mathrm{MOF} / \mathrm{CNTs}$ & 1021.8 & $800(82.1 \%)$ & $1 \mathrm{C}$ & $0.0224 \%$ & 15 \\
\hline $\begin{array}{l}\text { Interface-induced- } \\
\text { growth } \mathrm{Ni}_{3}(\mathrm{HITP})_{2}\end{array}$ & 851 & $500(84 \%)$ & $1 \mathrm{C}$ & $0.032 \%$ & 16 \\
\hline $\begin{array}{c}\mathrm{MOF} / \mathrm{G} \text { nanosheet } \\
\text { membrane }\end{array}$ & 882 & $500(94.2 \%)$ & $1 \mathrm{C}$ & $0.0116 \%$ & 17 \\
\hline $\mathrm{Zr}-\mathrm{Fc} \mathrm{MOF} / \mathrm{CNT}$ & 745 & $1500(59.5 \%)$ & $1 \mathrm{C}$ & $0.027 \%$ & 18 \\
\hline $\begin{array}{c}\mathrm{Bi}_{2} \mathrm{O}_{3} @ \mathrm{Co} / \mathrm{N}- \\
\mathrm{PC} @ \mathrm{~S}\end{array}$ & 853 & $500(89.9 \%)$ & $1.5 \mathrm{C}$ & $0.0213 \%$ & 19 \\
\hline 2D-Bi & 1093 & $200(78 \%)$ & $0.5 \mathrm{C}$ & $0.11 \%$ & 20 \\
\hline $\mathrm{BiOCl} / \mathrm{G}-\mathrm{S}$ & 1230 & $200(78.9 \%)$ & $0.2 \mathrm{C}$ & $0.105 \%$ & 21 \\
\hline Bi-MOF-1/rGO@PP & 960 & $1000(82.2 \%)$ & $1 \mathrm{C}$ & $0.0178 \%$ & $\begin{array}{l}\text { This } \\
\text { work }\end{array}$ \\
\hline
\end{tabular}




\section{References}

(1) Inge, A. K.; Koppen, M.; Su, J.; Feyand, M.; Xu, H.; Zou, X.; O'Keeffe, M.; Stock,

N., Unprecedented Topological Complexity in a Metal-Organic Framework Constructed from Simple Building Units. J. Am. Chem. Soc. 2016, 138, 1970-1976.

(2) Zhou, S.; Yang, S.; Ding, X.; Lai, Y.; Nie, H.; Zhang, Y.; Chan, D.; Duan, H.; Huang, S.; Yang, Z., Dual-Regulation Strategy to Improve Anchoring and Conversion of Polysulfides in Lithium-Sulfur Batteries. ACS Nano 2020, 14, 7538-7551.

(3) Chadi, D. J., Special Points for Brillouin-Zone Integrations. Phys. Rev. B 1977, $16,1746-1747$.

(4) Perdew, J. P.; Burke, K.; Ernzerhof, M., Generalized Gradient Approximation Made Simple. Phys. Rev. Lett. 1996, 77, 3865-3868.

(5) Kresse, G.; Joubert, D., From Ultrasoft Pseudopotentials to the Projector Augmented-Wave Method. Phys. Rev. B 1999, 59, 1758-1775.

(6) Abbas, S. A.; Ding, J.; Wu, S. H.; Fang, J.; Boopathi, K. M.; Mohapatra, A.; Lee,

L. W.; Wang, P. C.; Chang, C. C.; Chu, C. W., Modified Separator Performing Dual Physical/Chemical Roles to Inhibit Polysulfide Shuttle Resulting in Ultrastable Li-S Batteries. ACS Nano 2017, 11, 12436-12445.

(7) Kong, W.; Yan, L.; Luo, Y.; Wang, D.; Jiang, K.; Li, Q.; Fan, S.; Wang, J., Ultrathin $\mathrm{MnO}_{2} /$ Graphene Oxide/Carbon Nanotube Interlayer as Efficient PolysulfideTrapping Shield for High-Performance Li-S Batteries. Adv. Funct. Mater. 2017, 27, 1606663. 
(8) He, J.; Chen, Y.; Manthiram, A., Vertical $\mathrm{Co}_{9} \mathrm{~S}_{8}$ Hollow Nanowall Arrays Grown on a Celgard Separator as a Multifunctional Polysulfide Barrier for High-Performance Li-S Batteries. Energ. Environ. Sci. 2018, 11, 2560-2568.

(9) Lei, T.; Chen, W.; Lv, W.; Huang, J.; Zhu, J.; Chu, J.; Yan, C.; Wu, C.; Yan, Y.; He, W.; Xiong, J.; Li, Y.; Yan, C.; Goodenough, J. B.; Duan, X., Inhibiting Polysulfide Shuttling with a Graphene Composite Separator for Highly Robust Lithium-Sulfur Batteries. Joule 2018, 2, 2091-2104.

(10) Zhang, K.; Chen, Z.; Ning, R.; Xi, S.; Tang, W.; Du, Y.; Liu, C.; Ren, Z.; Chi, X.; Bai, M.; Shen, C.; Li, X.; Wang, X.; Zhao, X.; Leng, K.; Pennycook, S. J.; Li, H.; Xu, H.; Loh, K. P.; Xie, K., Single-Atom Coated Separator for Robust Lithium-Sulfur Batteries. ACS Appl. Mater. Inter. 2019, 11, 25147-25154.

(11) Ma, C.; Zhang, Y.; Feng, Y.; Wang, N.; Zhou, L.; Liang, C.; Chen, L.; Lai, Y.; Ji, X.; Yan, C.; Wei, W., Engineering Fe-N Coordination Structures for Fast Redox Conversion in Lithium-Sulfur Batteries. Adv. Mater. 2021, 33, 2100171.

(12) Yang, J. L.; Cai, D. Q.; Hao, X. G.; Huang, L.; Lin, Q.; Zeng, X. T.; Zhao, S. X.; Lv, W., Rich Heterointerfaces Enabling Rapid Polysulfides Conversion and Regulated $\mathrm{Li}_{2} \mathrm{~S}$ Deposition for High-Performance Lithium-Sulfur Batteries. ACS Nano 2021, 15, 11491-11500.

(13) Shen, J.; Xu, X.; Liu, J.; Wang, Z.; Zuo, S.; Liu, Z.; Zhang, D.; Liu, J.; Zhu, M., Unraveling the Catalytic Activity of Fe-Based Compounds Toward $\mathrm{Li}_{2} \mathrm{~S}_{\mathrm{x}}$ in Li-S Chemical System from D-P Bands. Adv. Energy Mater. 2021, 11, 2100673. 
(14) Xia, J.; Hua, W.; Wang, L.; Sun, Y.; Geng, C.; Zhang, C.; Wang, W.; Wan, Y.; Yang, Q. H., Boosting Catalytic Activity by Seeding Nanocatalysts onto Interlayers to Inhibit Polysulfide Shuttling in Li-S Batteries. Adv. Funct. Mater. 2021, 31, 2101980. (15) Hong, X. J.; Song, C. L.; Yang, Y.; Tan, H. C.; Li, G. H.; Cai, Y. P.; Wang, H., Cerium Based Metal-Organic Frameworks as an Efficient Separator Coating Catalyzing the Conversion of Polysulfides for High Performance Lithium-Sulfur Batteries. ACS Nano 2019, 13, 1923-1931.

(16) Zang, Y.; Pei, F.; Huang, J.; Fu, Z.; Xu, G.; Fang, X., Large-Area Preparation of Crack-Free Crystalline Microporous Conductive Membrane to Upgrade High Energy Lithium-Sulfur Batteries. Adv. Energy Mater. 2018, 8, 1802052.

(17) Liu, B.; Taheri, M.; Torres, J. F.; Fusco, Z.; Lu, T.; Liu, Y.; Tsuzuki, T.; Yu, G.;

Tricoli, A., Janus Conductive/Insulating Microporous Ion-Sieving Membranes for Stable Li-S Batteries. ACS Nano 2020, 14, 13852-13864.

(18) Wang, Y.; Deng, Z.; Huang, J.; Li, H.; Li, Z.; Peng, X.; Tian, Y.; Lu, J.; Tang, H.; Chen, L.; Ye, Z., 2D Zr-Fc Metal-Organic Frameworks with Highly Efficient Anchoring and Catalytic Conversion Ability Towards Polysulfides for Advanced Li-S Battery. Energy Storage Mater. 2021, 36, 466-477.

(19) Liu, H.; Chen, Z.; Zhou, L.; Li, X.; Pei, K.; Zhang, J.; Song, Y.; Fang, F.; Che, R.; Sun, D., Rooting Bismuth Oxide Nanosheets into Porous Carbon Nanoboxes as a Sulfur Immobilizer for Lithium-Sulfur Batteries. J. Mater. Chem. A 2019, 7, 7074-7081. 
(20) Xu, H.; Yang, S.; Li, B., Ultrathin Bismuth Nanosheets as an Efficient Polysulfide Catalyst for High Performance Lithium-Sulfur Batteries. J. Mater. Chem. $A$ 2020, $8,149-157$.

(21) Wu, X.; Liu, N.; Wang, M.; Qiu, Y.; Guan, B.; Tian, D.; Guo, Z.; Fan, L.; Zhang, N., A Class of Catalysts of BiOX $(\mathrm{X}=\mathrm{Cl}, \mathrm{Br}, \mathrm{I})$ for Anchoring Polysulfides and Accelerating Redox Reaction in Lithium Sulfur Batteries. ACS Nano 2019, 13, 1310913115. 